\title{
Surgical anatomy and utility of pedicled vascularized tissue flaps for multilayered repair of skull base defects
}

\author{
Sam Safavi-Abbasi, MD, PhD, ${ }^{1}$ Noritaka Komune, MD, PhD, ${ }^{2}$ Jacob B. Archer, BS, ${ }^{3}$ \\ Hai Sun, MD, PhD, ${ }^{1}$ Nicholas Theodore, MD, ${ }^{1}$ Jeffrey James, MD, DDS, ${ }^{3}$ Andrew S. Little, MD, ${ }^{1}$ \\ Peter Nakaji, MD, ${ }^{1}$ Michael E. Sughrue, MD, ${ }^{3}$ Albert L. Rhoton, MD, ${ }^{2}$ and Robert F. Spetzler, MD ${ }^{1}$ \\ 'Department of Neurosurgery, Barrow Neurological Institute, St. Joseph's Hospital and Medical Center, Phoenix, Arizona, \\ ${ }^{2}$ Department of Neurological Surgery, University of Florida, Gainesville, Florida, and ${ }^{3}$ Department of Oral and Maxillofacial \\ Surgery, University of Oklahoma Health Science Center, Oklahoma City, Oklahoma
}

OBJECTIVE The objective of this study was to describe the surgical anatomy and technical nuances of various vascularized tissue flaps.

METHODS The surgical anatomy of various tissue flaps and their vascular pedicles was studied in 5 colored siliconeinjected anatomical specimens. Medical records were reviewed of 11 consecutive patients who underwent repair of extensive skull base defects with a combination of various vascularized flaps.

RESULTS The supraorbital, supratrochlear, superficial temporal, greater auricular, and occipital arteries contribute to the vascular supply of the pericranium. The pericranial flap can be designed based on an axial blood supply. Laterally, various flaps are supplied by the deep or superficial temporal arteries. The nasoseptal flap is a vascular pedicled flap based on the nasoseptal artery. Patients with extensive skull base defects can undergo effective repair with dual flaps or triple flaps using these pedicled vascularized flaps.

CONCLUSIONS Multiple pedicled flaps are available for reconstitution of the skull base. Knowledge of the surgical anatomy of these flaps is crucial for the skull base surgeon. These vascularized tissue flaps can be used effectively as single or combination flaps. Multilayered closure of cranial base defects with vascularized tissue can be used safely and may lead to excellent repair outcomes.

http://thejns.org/doi/abs/10.3171/2015.5.JNS15529

KEY WORDS cerebrospinal fluid leak; skull base fractures; skull base reconstruction; surgical technique; temporoparietal fascia

$\mathrm{T}$ HE frontal bones split anteriorly into plates that enclose the frontal sinuses and posteriorly to form the anterior cranial base. ${ }^{30}$ In the midline, interposed between the frontal bones, are the ethmoid bones containing the ethmoid air cells, the site of the crista galli, and the cribriform plate. The frontal and ethmoid bones join the sphenoid bone, which encompasses the sphenoid sinus. ${ }^{30}$ Defects in the skull base involve these intimately associated paranasal, cranial, and intracranial structures.

Neoplasms or extensive traumatic fractures that involve the thin bones over the paranasal sinuses may result in large bone defects with the potential to lead to complications such as CSF leak and meningitis..$^{10,13,27,28}$ Thus, the successful outcome of skull base surgery ultimately depends on reconstruction of the skull base and healing of the surgical site. It has been well established that using a vascularized tissue flap to repair large skull base defects promotes fast and durable healing. ${ }^{35}$ Multilayered closure for large skull base defects has been reported to be crucial in preventing delayed brain sagging and CSF leaks. . $^{14,17,24}$ Furthermore, in a recent meta-analysis, Harvey et al. ${ }^{19}$ showed that skull base reconstruction with pedicled flaps

ABBREVIATIONS NSF = nasoseptal flap; STA = superficial temporal artery.

SUBMITTED March 6, 2015. ACCEPTED May 14, 2015.

INCLUDE WHEN CITING Published online November 27, 2015; DOI: 10.3171/2015.5.JNS15529. 
significantly lowers the rate of postoperative CSF leaks compared with reconstruction with free grafts. For this reason, pedicled flaps, such as the anteriorly based pericranial, temporoparietal fascial, temporalis muscle, and galeopericranial flaps, are frequently used to reconstruct the cranial base. ${ }^{6,7,9,15-17,19,23,24,26,31,32,37}$ More recently, endoscopic endonasal approaches have been popularized and a vascular pedicled flap of the nasal septum based on the nasoseptal artery (Hadad-Bassagasteguy flap or nasoseptal flap [NSF]) has also been introduced for skull base repair and is used extensively. ${ }^{17,24}$

The aim of this report is to detail the surgical and anatomical properties of these versatile pedicled tissue flaps and to establish the technical nuances for multilayered skull base repair in clinical cases where these flaps may be used in combination.

\section{Methods}

\section{Anatomical Dissection}

Five formalin-perfused adult cadaveric heads were used for this study. The arteries and veins were injected with red or blue silicone rubber (Dow Corning Corp.), Thinner 200 (Dow Corning Corp.), and an RTV catalyst (Dow Corning Corp.), and then dissected and studied. The cadaver dissections followed the steps of the surgical procedure. The specimens were cut sagittally to dissect the sphenopalatine artery, posterior septal artery, and nasal septum. Dissection was performed of the temporalis fascia-pericranial flap, the temporoparietal fascial flap, the anteriorly based pericranial flap, and the NSF. All anatomical specimens were dissected at the Surgical Neuroanatomy Laboratory at the University of Florida in Gainesville, Florida.

\section{Surgical Cases}

After approval from the University of Oklahoma Medical Center Institutional Review Board, we performed a retrospective chart review of 11 consecutive patients who had undergone surgical repair of a CSF fistula because of extensive fractures of the anterior skull base. All 11 patients were treated at the University of Oklahoma Medical Center between January 2009 and July 2014. All repairs included various combinations of the temporalis fasciapericranial flap, the temporoparietal fascial flap, the anteriorly based pericranial flap, and the NSF. The NSF was used either primarily during initial repair or as a salvage procedure after failed initial repair with an anteriorly based pericranial flap. Patients with simple fractures who were managed with only 1 flap were not included (Table 1 ).

\section{Results}

\section{Surgical Anatomy of the Scalp}

The numerous layers of well-vascularized tissue that constitute the scalp allow for several flap options during flap selection for skull base repair. The scalp consists of skin, subcutaneous tissue, galea aponeurotica, subgaleal loose connective tissue, and periosteum (Fig. 1). The subcutaneous layer is adherent to the overlying skin and the underlying galea aponeurotica. The galea aponeurotica is a layer of dense fibrous tissue that blends anteriorly with the frontalis muscle and posteriorly with the occipitalis muscle and is contiguous with the temporoparietal fascia at the superior temporal line (Fig. 2). The subgaleal fascia and the adherent periosteum overlying the skull define the pericranium, which is contiguous with the deep temporal fascia in the temporal region. The blood supply to the pericranium is derived from several sources located anteriorly, laterally, and posteriorly. Lateral dissection is performed in the same plane superficial to the superficial layer of the temporal fascia to within $2-4 \mathrm{~cm}$ of the body of the $\mathrm{zy}-$ goma and the zygomatic arch (Fig. 3).

The supraorbital, supratrochlear, superficial temporal, greater auricular, and occipital arteries all contribute to the vascular supply of the pericranium (Fig. 4). Within the pericranium, there is an extensive interconnection of axial vessels, as well as communication with perforators arising from the calvaria. The deep divisions of the supraorbital and supratrochlear vessels vascularize the pericranium anteriorly. After rising from the bony foramina at the superior orbital rims, both vessels divide into a larger superficial vessel, which traverses the galea aponeurotica and runs cephalad to the pericranium in an axial orientation. Laterally, these multiple axial vessels that supply the pericranium in the temporoparietal area can be demonstrated by injecting red and blue silicone rubber into the superficial temporal arteries (STAs) and veins (Figs. 1-3). The STA divides into anterior and posterior branches approximately $2 \mathrm{~cm}$ superior to the zygomatic arch. The anterior branch supplies blood to the temporoparietal fascial, galeal, and galeopericranial flaps. The middle temporal artery is a branch of the STA that usually originates $0.5-2$ $\mathrm{cm}$ below the zygomatic arch. The middle temporal artery enters the deep temporal fascia immediately superior to the zygomatic arch and continues superiorly. It sends perforators into the temporalis muscle, where anastomoses are built with the deep temporal artery, which is a branch of the internal maxillary artery. Posteriorly, the occipital artery and the greater auricular artery supply the pericranium. Inferior and deep to the pericranium lies the temporalis muscle within the temporal fossa. This muscle receives its blood supply from the anterior and posterior deep temporal arteries, which arise from the internal maxillary system deep to the zygomatic arch. Additional blood supply is derived from the middle temporal artery, which originates in the STA and enters the muscle laterally.

Thus, laterally, the deep or STAs supply blood to various flaps that can then be obtained and used as vascularized flaps (Figs. 4-6). The pedicled temporalis muscle flap is a reliable, highly versatile flap composed of the temporalis muscle and the overlying temporalis fascia. This vascularized flap is based on the anterior and posterior deep temporal arteries. The pericranium in this area, which is firmly attached to the deep fascia of the temporalis muscle, is supplied by the superficial temporal vessels and can be elevated together with the fascia (Figs. 5 and 6). In contrast, the temporoparietal fascial flap or the galeal flap is a pedicled flap based laterally on the STAs (Figs. 2 and 3 ). These highly vascularized lateral flaps are an excellent source for repair of skull base defects and will be detailed separately in the following sections. 
TABLE 1. Demographics of 11 patients with extensive skull base fractures repaired with combination vascularized flaps

\begin{tabular}{|c|c|c|c|c|c|c|c|c|}
\hline $\begin{array}{l}\text { Patient } \\
\text { No. }\end{array}$ & $\begin{array}{l}\text { Age } \\
\text { (yrs) }\end{array}$ & $\begin{array}{l}\text { Admission } \\
\text { GCS Score }\end{array}$ & Etiology & Fractures & Repairs & $\begin{array}{l}\text { GOS } \\
\text { Score }\end{array}$ & $\begin{array}{c}\mathrm{FU} \\
(\mathrm{mos})\end{array}$ & $\begin{array}{l}\text { Complication; } \\
\text { CSF Leak }\end{array}$ \\
\hline 1 & 30 & 15 & MVC & $\begin{array}{l}\text { Frontal, ethmoid, \& } \\
\text { sphenoid sinuses }\end{array}$ & $\begin{array}{l}\text { Salvage NSF } 1 \text { month after } \\
\text { initial anterior pericranial } \\
\text { flap repair }\end{array}$ & 5 & 43 & $\begin{array}{l}\text { None; no CSF leak after } \\
\quad \text { NSF }\end{array}$ \\
\hline 2 & 22 & 5 & MVC & $\begin{array}{l}\text { Frontal sinus, petrous, \& } \\
\text { sphenoid wing }\end{array}$ & $\begin{array}{l}\text { Salvage NSF in same hospital } \\
\text { course after initial anterior } \\
\text { pericranial flap repair }\end{array}$ & 3 & 29 & $\begin{array}{l}\text { None; no CSF leak after } \\
\quad \text { NSF }\end{array}$ \\
\hline 3 & 58 & 8 & Tree limb fall & $\begin{array}{l}\text { Frontal \& sphenoid } \\
\text { sinuses, petrous por- } \\
\text { tion of temporal bone }\end{array}$ & $\begin{array}{l}\text { Salvage NSF } 3 \text { mos after } \\
\text { initial repair w/ anterior } \\
\text { pericranial flap }\end{array}$ & 5 & 13.1 & $\begin{array}{l}\text { None; no CSF leak after } \\
\quad \text { NSF }\end{array}$ \\
\hline 4 & 21 & 14 & MCC & $\begin{array}{l}\text { Frontal, ethmoid, \& } \\
\text { sphenoid sinuses }\end{array}$ & APF \& NSF & 5 & 4.8 & None; no CSF leak \\
\hline 5 & 25 & 15 & $\begin{array}{l}\text { Air tank explo- } \\
\text { sion }\end{array}$ & $\begin{array}{l}\text { Frontal \& ethmoid } \\
\text { sinuses }\end{array}$ & Lateral TFPF \& APF & 5 & 1.4 & None; no CSF leak \\
\hline 6 & 36 & 15 & MCC & $\begin{array}{l}\text { Frontal, ethmoid, \& } \\
\text { sphenoid sinuses; } \\
\text { sphenoid wing \& } \\
\text { temporal bone }\end{array}$ & Lateral TFPF \& APF & 5 & 3 & None; no CSF leak \\
\hline 7 & 22 & 13 & MVC & $\begin{array}{l}\text { Frontal sinus \& sphe- } \\
\text { noid bone }\end{array}$ & Lateral TFPF \& APF & 3 & 2.6 & None; no CSF leak \\
\hline 8 & 57 & 3 & $\begin{array}{l}\text { Pool pump } \\
\quad \text { explosion }\end{array}$ & $\begin{array}{l}\text { Frontal \& sphenoid } \\
\quad \text { sinuses }\end{array}$ & Lateral TFPF, APF, \& NSF & 3 & 2.5 & $\begin{array}{l}\text { Chronic dehiscence } \\
\text { (resolved after wound } \\
\text { revision); no CSF } \\
\text { leak }\end{array}$ \\
\hline 9 & 56 & 3 & MCC & $\begin{array}{l}\text { Frontal, ethmoid, \& } \\
\text { sphenoid sinuses }\end{array}$ & Lateral TFPF, APF, \& NSF & 4 & 4.2 & None; no CSF leak \\
\hline 10 & 27 & 3 & $\begin{array}{l}\text { Lead pipe to } \\
\text { head }\end{array}$ & $\begin{array}{l}\text { Frontal, ethmoid, \& } \\
\text { sphenoid sinuses }\end{array}$ & Lateral TFPF \& APF & 5 & 7.5 & None; no CSF leak \\
\hline 11 & 35 & 15 & $\begin{array}{l}\text { NF1 (malignant- } \\
\text { peripheral } \\
\text { nerve sheath } \\
\text { tumor) }\end{array}$ & $\begin{array}{l}\text { Sphenoid sinus defect } \\
\text { after gross-total re- } \\
\text { section of trigeminal } \\
\text { schwannoma }\end{array}$ & $\begin{array}{l}\text { Tumor resection \& lateral } \\
\text { TFPF, followed by endona- } \\
\text { sal resection \& NSF }\end{array}$ & 5 & 6.6 & None; no CSF leak \\
\hline
\end{tabular}

APF = anterior pericranial flap; FU = follow-up; GCS = Glasgow Coma Scale; GOS = Glasgow Outcome Scale; MCC = motorcycle collision; MVC = motor vehicle collision; NF1 = neurofibromatosis type $1 ;$ TFPF = temporalis fascia-pericranial flap.

\section{Pericranial Flap Design and Temporalis Muscle Fascia-Parietal Pericranial Flap}

The pericranial flap can be designed based on its axial blood supply (Fig. 6). The anteriorly based flap receives its blood supply primarily from the supraorbital and supratrochlear arteries. It can be designed unilaterally or widely using a bilateral blood supply. However, pericranial flaps of considerable size may be based on either side of the temporoparietal skull. Such flap design may be unilateral or bilateral and may include the temporalis fascia inferiorly (Table 2).

For the unilateral temporalis fascia-pericranial flap, the pericranium can be designed for a laterally based flap (Figs. 5 and 6). The pericranium can be incised contralaterally to the pedicle of the flap at the proposed marked lines, with a subperiosteal dissection that ensues laterally toward the superior temporal line. The elevation of the sheet of pericranium, together with the temporalis fascia and muscle, continues toward the contralateral side to the level of the zygoma. This fascial/pericranial flap is then elevated off the temporalis muscle bluntly toward the ipsilateral side, where the vascular pedicle is formed that contains a deep temporal supply. While remaining pedicled, the flap is lifted out of the surgical field (Fig. 6). The anteriorly based flap can then be dissected in the subperiosteal plane to the orbital rims, as in the standard exposure, which creates a dual flap for repair (Figs. 5 and 6). The pedicled temporalis fascia-pericranial flap sheet is an excellent flap with a versatile arc of rotation and adequate length for extensive skull base reconstruction (Table 2 ); the temporalis muscle itself is seldom used for reconstruction and is sutured back to the anterior part of the temporal fossa to help decrease postoperative temporal fossa hollowing and poor cosmesis (Fig. 6). A vascularized temporalis fascia-pericranial flap of $14-20 \mathrm{~cm}$ can be dissected and used for tissue transfer (Fig. 6).

\section{Temporoparietal Fascial Flap}

The galea aponeurotica is usually tightly attached to 


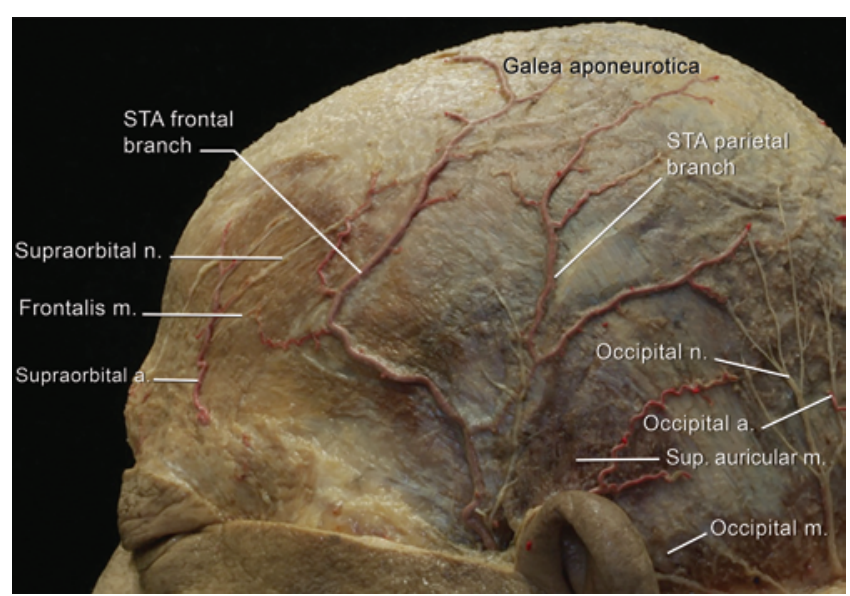

FIG. 1. Vascular anatomy of the galea and pericranium. After removal of the skin and subcutaneous layers, the galea aponeurotica is visualized. The galea is continuous with the frontalis muscle anteriorly and the temporoparietal muscle inferiorly. The parietotemporal artery passes through the temporoparietal fascia. The supraorbital and supratrochlear arteries supply the anterior pericranium deeper to the temporoparietal fascia. The greater auricular, occipital arteries, and veins all contribute to the vascular supply of the occipital pericranium. $\mathrm{a}_{\text {. }}=$ artery; $\mathrm{m}$. = muscle; $n .=$ nerve; Sup. = superior. Figure is available in color online only. the skin and the subcutaneous tissue, making separation relatively difficult. However, it is more mobile superiorly on the firmly adherent pericranium and inferiorly on the temporalis muscle, from which it is separated by the subgaleal fascia (Figs. 2, 4, and 5; Table 2). Thus, beginning the dissection inferiorly near the ear, and then working cephalad, facilitates identification of the correct plane. Before dissection of the flap is initiated, the vascular pedicle should be identified that contains the STA and the vein anterior to the tragus. Here, the artery measures 1.8-2.4 $\mathrm{mm}$ in diameter and is usually posterior to the larger vein. Damage to the hair follicles can be avoided by dissecting the temporoparietal flap under microscopic magnification just deep to the cutaneous follicles (Fig. 2).

With the operative microscope, the endocranial surface of the skull base is inspected posterior to the planum sphenoidale and the sphenoid wing. For repair of the cranial base, the pedicled flap is placed extradurally along the anterior floor of the skull, and then sutured to the dura for a watertight seal with the use of the operative microscope. A posterior-releasing incision must be made in the laterally based temporalis flap to allow proper rotation into the cranial cavity (Fig. 6).
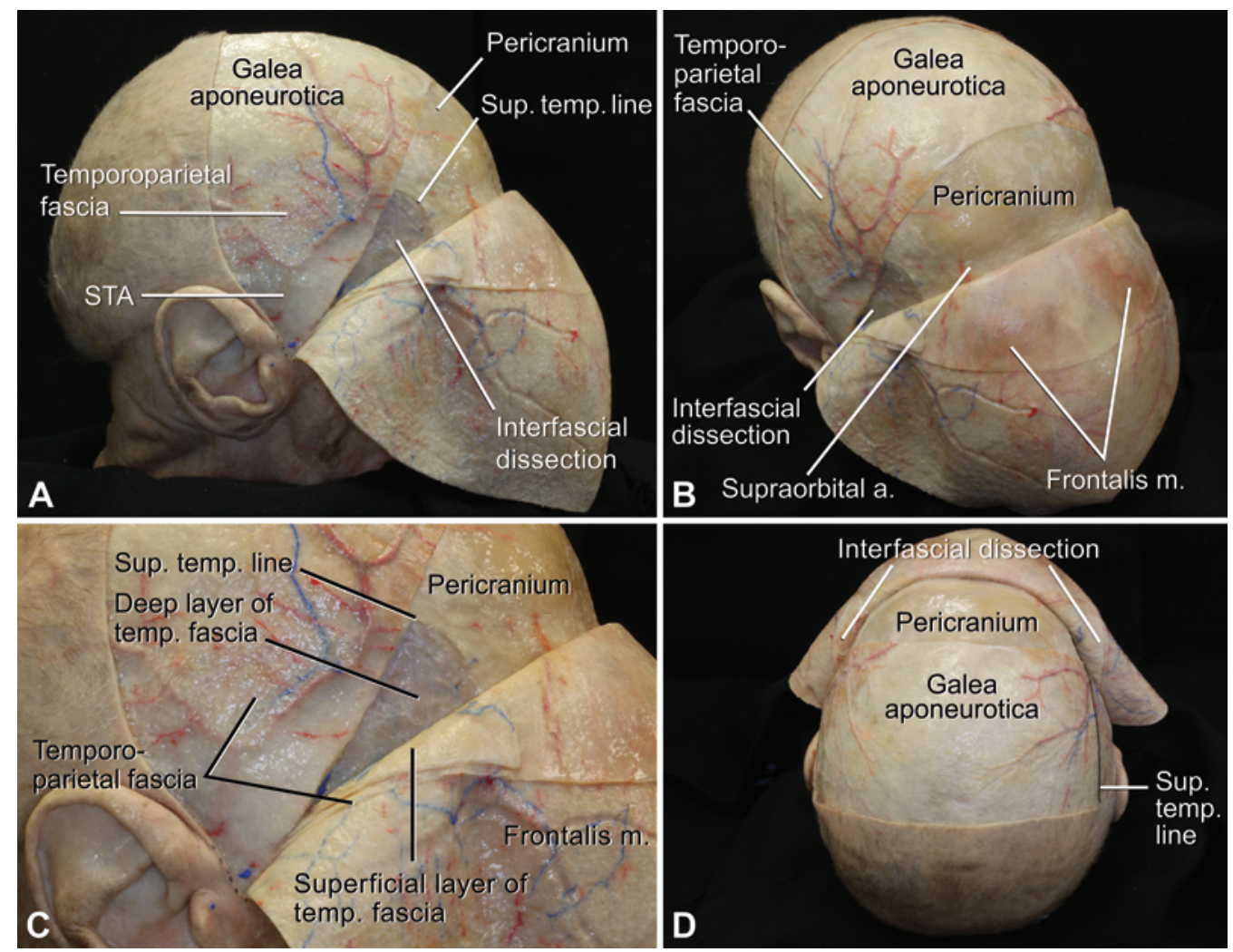

FIG. 2. Lateral (A), superolateral (B), close-up lateral (C), and superior (D) views of interfascial dissection for preservation of the facial nerve. The interfascial dissection should be performed to preserve the frontal branches of the facial nerve, which traverse the temporoparietal fascia toward the frontal muscle after crossing over the zygoma. After interfascial dissection, the temporoparietal fascia and the superficial layer of the temporal fascia are reflected anteriorly with the skin flap, and the deep layer of the temporal fascia is exposed. The bilateral interfascial dissection extends over the superior temporal line to the frontal region, and the pericranium is exposed. The areolar layer in the frontal region is identified between the galea aponeurotica and the pericranium and should be left on the pericranium. The pericranium in the frontal region is supplied by the supraorbital and supratrochlear arteries. $a_{.}=$artery; $\mathrm{m} .=$ muscle; Sup. $=$ superior; temp. = temporal. Figure is available in color online only. 

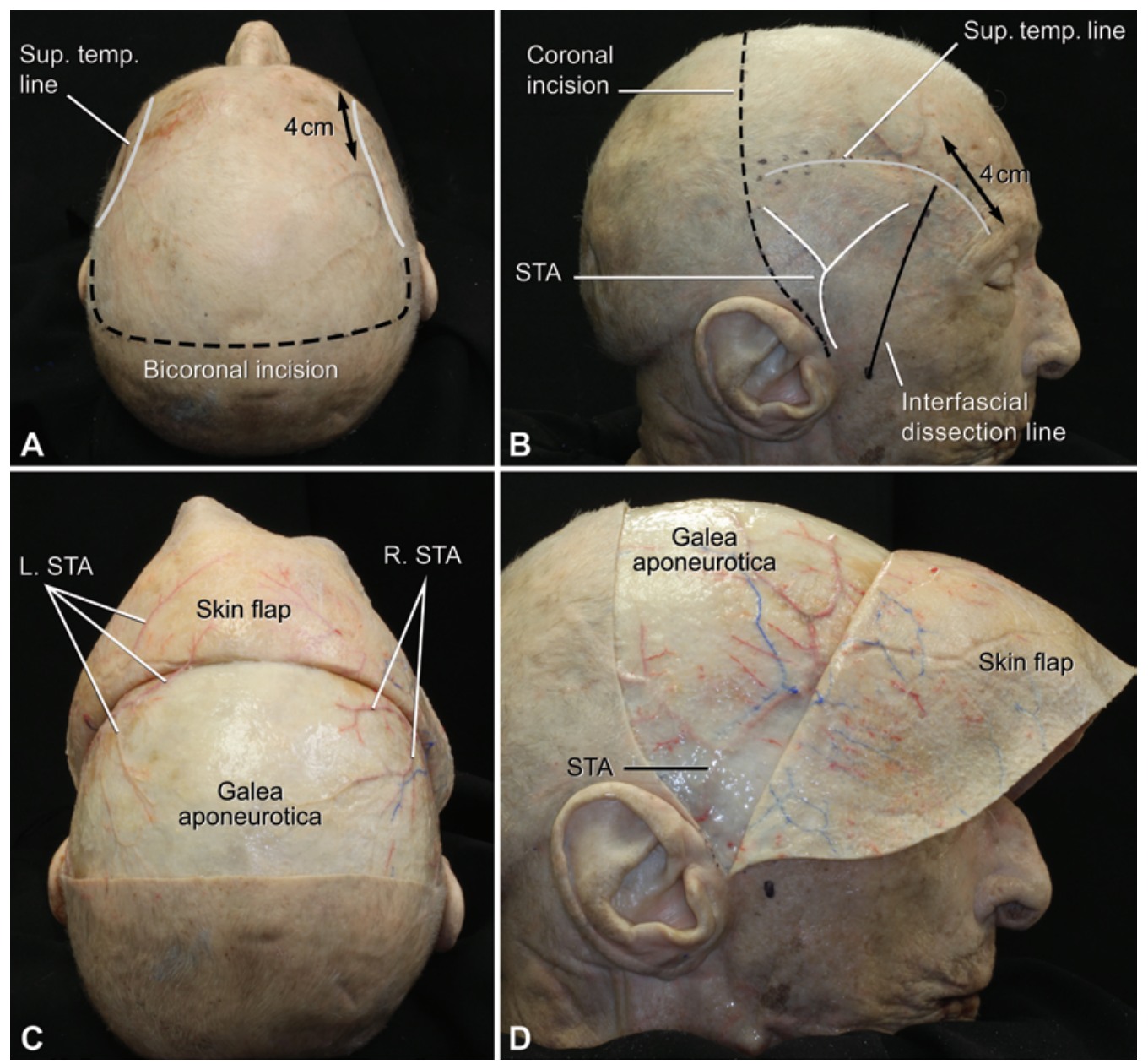

FIG. 3. Skin incision and flap. A and B: Superior (A) and lateral (B) views of the skin incision. Bicoronal skin incision (dashed line) to make the skin flap and expose the temporoparietal fascia. The skin flap is extended to the line where the interfascial dissection should be started $4 \mathrm{~cm}$ superoposterior to the superior orbital rim (black line). C and D: Superior (C) and lateral (D) views of the skin flap. After elevation of the skin flap, the galea aponeurotica is exposed and is continuous with the temporoparietal fascia, through which the STA can be seen ascending superiorly. L. = left; R. = right; Sup. = superior; temp. = temporal. Figure is available in color online only.

\section{Nasoseptal Flap}

The endoscopic endonasal approach and repair with an NSF can be performed for extensive fractures involving large defects in the sphenoid and ethmoid sinuses or as a salvage procedure when other flaps have been used and patients have persistent CSF leaks (Table 2). In this procedure, a minimally invasive approach to the sphenoid is used that is similar to the approach for sella turcica lesions. A blunt elevator is used to lateralize the middle turbinate. Repair then proceeds with elevation of the NSF, as described recently. ${ }^{17,24,38}$

In general, the nasal septum is highly vascularized by branches of the sphenopalatine artery, the anterior and posterior ethmoid arteries, and the greater palatine and labial arteries. The NSF can be designed based on the nasoseptal artery, which is a terminal branch of the internal maxillary artery, according to the size and shape of the skull base defect (Figs. 7 and 8).

Within the pterygopalatine fossa, the maxillary artery terminates as the sphenopalatine artery and descending palatine arteries (Figs. 7 and 8). The sphenopalatine artery then divides into the posterior lateral nasal artery and the posterior septal artery. The posterior septal artery originates usually just before the sphenopalatine foramen within the pterygopalatine fossa (Fig. 8). Therefore, in most cases more than 1 vessel will traverse the sphenopalatine foramen. After the posterior lateral nasal artery passes through the sphenopalatine foramen, it courses inferiorly and vertically. The posterior septal artery passes through the sphenopalatine foramen and then runs on the anterior wall of the sphenoid sinus between the sphenoid ostium and the choana to reach the posterior aspect of the nasal septum (Fig. 8). The posterior septal artery then bifurcates into a superior branch and an inferior branch. It is important to preserve this posterolateral neurovascular pedicle while elevating the flap from the anterior face of the sphenoid sinus (Fig. 8) The sphenopalatine foramen lies just above the level of the attachment of the middle turbinate (Fig. 8). The NSF is harvested by making a vertical incision, using a no. 11 or no. 15 blade on a long handle, on the 

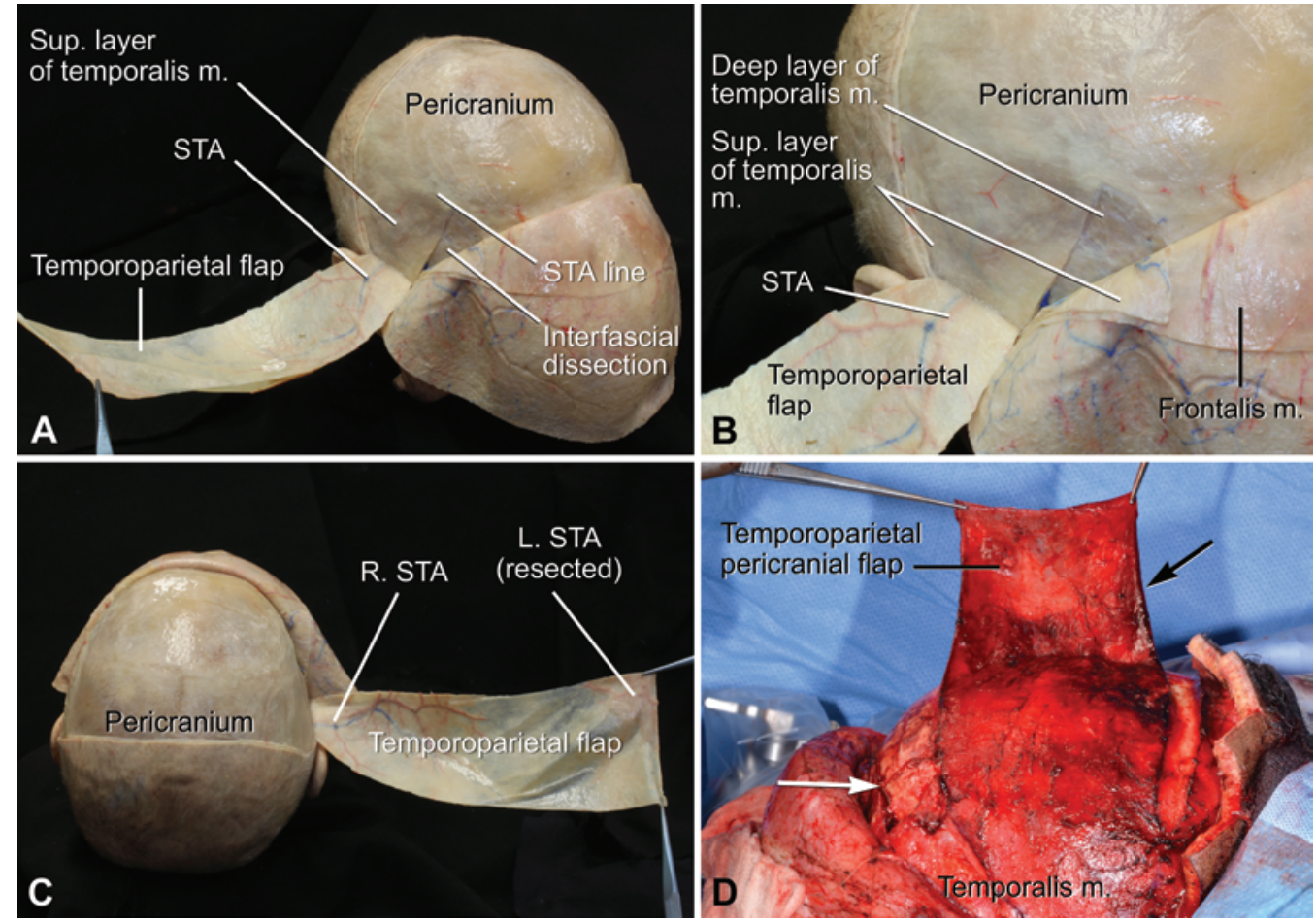

FIG. 4. A-C: Superolateral (A), close-up superolateral (B), and superior superolateral $(C)$ views of the laterally based temporoparietal flap. After elevation of the skin flap, the right laterally based temporoparietal flap is elevated after dissection of the contralateral STAs. This fascia is elevated off the temporalis fascia bluntly toward the right side, where the vascular pedicle is formed. The flap is pedicled by the right STA. Within the pericranium, there is extensive interconnection of axial vessels, as well as communication with perforators arising from the calvaria. D: Intraoperative photograph of a patient with significant comminuted frontal bone fractures precluding the use of anteriorly based pericranium (white arrow). In this case, however, the parietal pericranium was preserved and could be elevated with the temporalis muscle fascia, which lies below and inferior. The vascular supply of this laterally based temporoparietal-pericranial flap (black arrow) is based on both superficial and deep temporal vessels. $L$. = left; $\mathrm{m}$. $=$ muscle; R. = right; Sup. = superior. Figure is available in color online only.

nasal septum anterior to the middle turbinate at the bonecartilaginous junction. The flap is raised in a subperiosteal-subperichondrial plane back to the sphenoid rostrum. The inferior incision follows the free edge of the posterior septum and then crosses the posterior choana. The size of the flap can be tailored to the reconstruction needs of the patient, and the inferior incision may be designed to include the mucoperiosteum within the floor of the nose (Fig. 8). The superior incision extends laterally to cross the rostrum of the sphenoid sinus at the level of its natural ostium. The cranial incision should be placed below the area of the olfactory epithelium. Once inferior and superior cuts are made to free the flap, it can then be rotated (Fig. 7). A highly vascularized, posteriorly pedicled flap has an excellent arc of rotation; however, it is important to ensure that the vascular pedicle does not twist in upon itself (Fig. 7). The flap can be rotated toward the ventral skull base with the mucoperichondrial/mucoperiosteal surface of the NSF in direct contact with the ventral skull base defect.

\section{Discussion}

\section{Pericranial Flap Design}

Prior to the routine use of vascularized tissue flaps for skull base reconstruction, free grafts of biological or syn- thetic material were used as the primary reconstructive technique., ${ }^{4}, 18$ However, the repair of large defects using free grafts may result in rates of postoperative CSF leaks of up to $40 \% .^{14,18,20}$ Classic repair of the anterior skull base uses an anteriorly based pericranial flap as the primary means to repair anterior cranial floor defects due to multiple etiologies. ${ }^{3,21,23,33,35}$ Its popularity can be attributed to various factors. It is an easy flap to harvest, and it does not often require additional incisions. $3,21,23,33,35$ It also has a rich blood supply from the supraorbital and supertrochlear arteries, which ensures viability and allows for its quick incorporation into the surrounding tissue. ${ }^{3}$ However, various problems with this flap have been identified, and $10 \%-17 \%$ of patients have persistent CSF leaks after initial repair, which suggests flap failure. ${ }^{10,13,34}$ Furthermore, the length of the anteriorly based pericranium is limited and has a limited arc of rotation that reduces the versatility of this flap. Trauma to the anterior forehead (comminuted fractures, radiation treatment, and extensive tumors) may compromise the vascular supply from the supraorbital and supratrochlear arteries, potentially obviating this flap design in some cases.$^{35}$ However, as shown in our study, the design of the pericranial flap can be based on its axial blood supply. The laterally based pericranial flap is a pedicled vascularized flap based on 

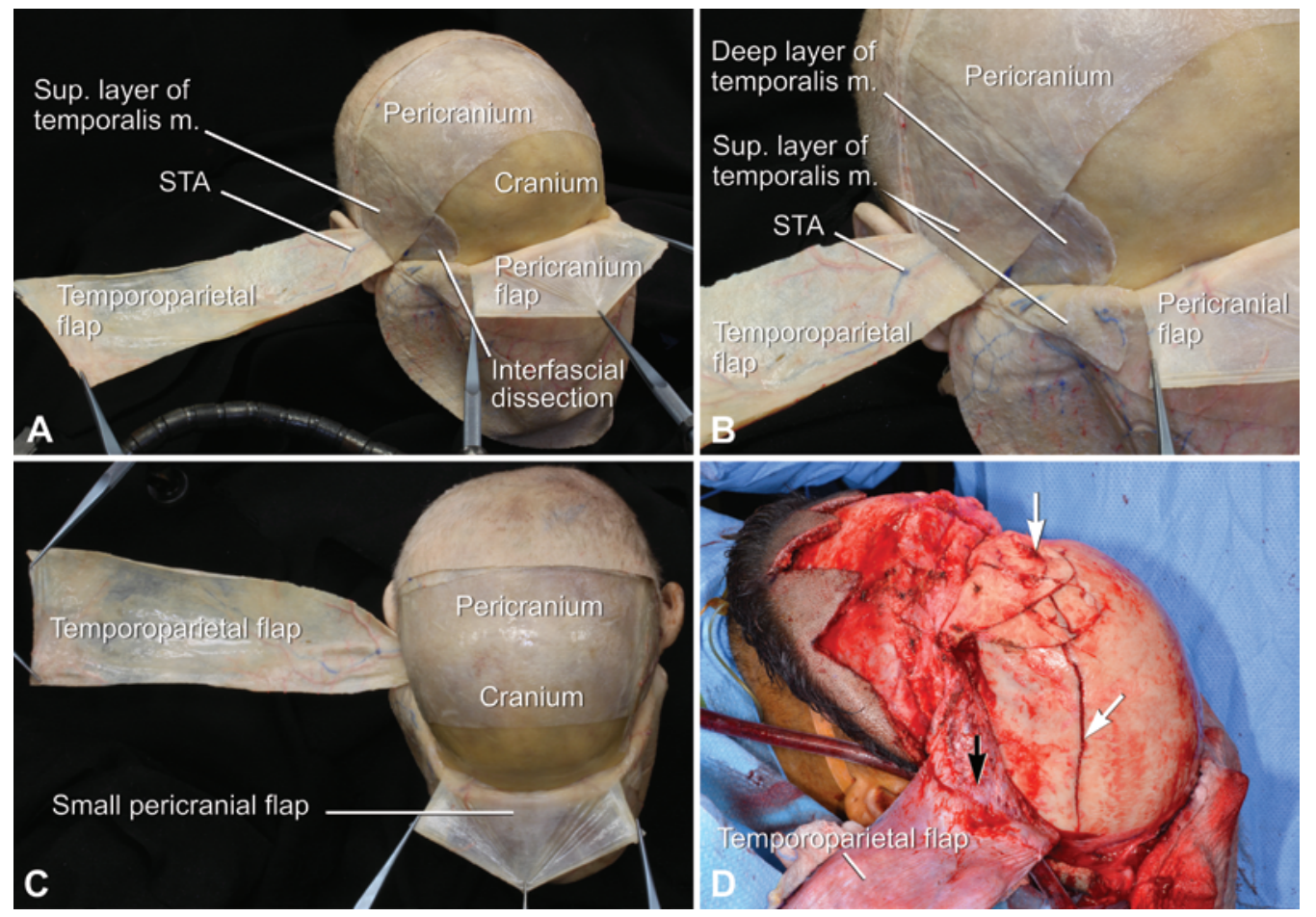

FIG. 5. Superolateral (A), close-up superolateral (B), and superior superolateral (C) views of a small frontal pericranial flap, and an intraoperative photograph (D) of a patient with a comminuted frontal fracture. The small frontal pericranial flap has been elevated. This flap is pedicled by the supraorbital and supratrochlear arteries. In these dissections $(A-C)$, a dual flap has been formed on the right side, with a temporoparietal fascial flap pedicled on the STA. Note that the anteriorly based pericranial flap has a relatively small surface area and a limited arc of rotation. The laterally based temporoparietal fascial flap is $14-20 \mathrm{~cm}$ long, with a large surface area and an excellent rotational arc. The temporalis muscle receives blood supply from the anterior and posterior deep temporal arteries, which arise from the internal maxillary system deep to the zygomatic arch (not shown). Additional blood supply is derived from the middle temporal artery, originating from the STA and entering the muscle laterally. In the cadaveric dissections, the temporoparietal pericranium has not been elevated. The pericranium in this area is firmly attached to the deep fascia of the muscle and is supplied by the superficial temporal vessels and can be elevated together with the muscle and its fascia. In the intraoperative photograph (D), the comminuted frontal bone fractures have significantly limited the utility of the anteriorly based pericranium. Therefore, a laterally based vascularized flap using the temporalis muscle has been elevated. The pedicle of the flap (black arrow) is based on the superficial and deep temporal arteries, which are unaffected by the fractures (white arrows). $\mathrm{m}$. = muscle; Sup. = superior. Figure is available in color online only.

the superficial and deep temporal arteries. ${ }^{3}$ The highly vascular nature of this layer allows the design of a multitude of flaps that can be used for local tissue transfer. ${ }^{3}$ Laterally, various flaps supplied by the deep or STAs can be obtained and used as vascularized flaps. The temporalis muscle flap comprises the temporalis muscle and the overlying temporalis fascia. ${ }^{1,2,5,8}$ It is a vascularized flap based on the anterior and posterior deep temporal arteries., ${ }^{1,2,5,8}$ As demonstrated in our anatomical dissection and clinical cases, the pericranium in this area is firmly attached to the deep temporalis muscle fascia and can be elevated together with the fascia. The pedicled fascia-pericranium sheet gives rise to a long, versatile flap that is usually sufficient for extensive cranial base reconstruction. Therefore, the temporalis muscle itself does not need to be used for reconstruction, which avoids postoperative temporal fossa hollowing, poor cosmesis, and jaw movement limitations. However, if needed, the posterior aspect of the muscle can be divided and used as a flap with satisfactory cosmetic results. ${ }^{1,2,5,8}$

\section{Temporoparietal Fascial Flap}

The temporoparietal fascial flap or galeal flap is a vascularized flap based laterally on the superficial temporal vessels. Laterally based temporoparietal fascial flaps have been used in many areas, especially in head and neck reconstruction. ${ }^{32}$

Taha et al. ${ }^{36}$ described the use of temporoparietal fascial flaps for repair of a large traumatic middle cranial fossa CSF fistula via a middle cranial fossa approach. However, the disadvantage of this flap is potential damage to the hair follicles that results in postoperative alopecia..$^{35}$ Additionally, dissection of the galeal layer from the subcutaneous tissue may cause scalp necrosis. ${ }^{35}$ Therefore, we reserve this flap for use in patients with no laterally based pericranium available.

\section{Nasoseptal Flap}

More recently, a vascular pedicled flap of the nasal septum mucoperiosteum and mucoperichondrium based on the nasoseptal artery (Hadad-Bassagasteguy flap/NSF) 

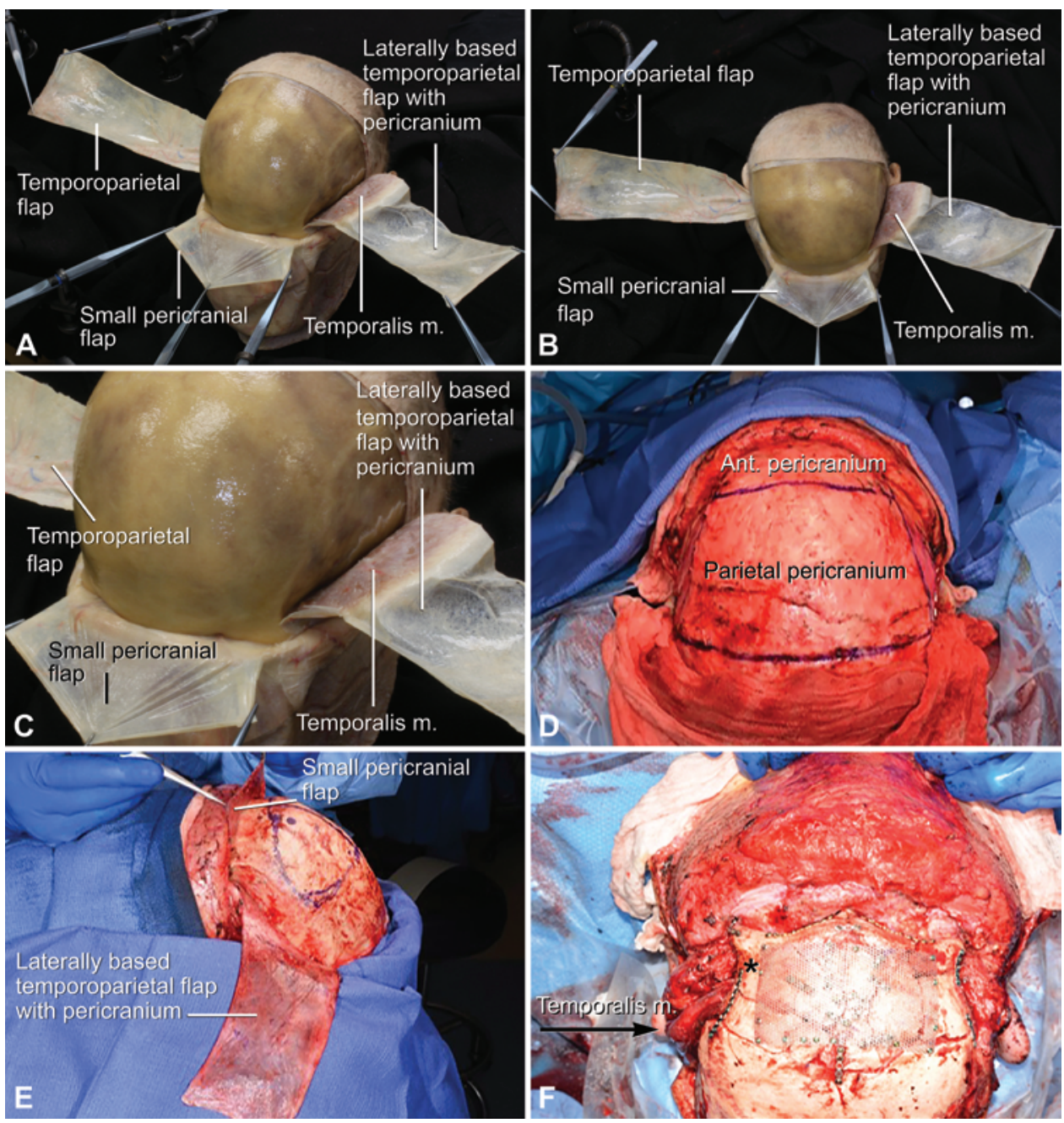

FIG. 6. A-C: Superolateral (A), superior (B), and close-up superolateral $(C)$ views of potentially harvested flaps for the frontal skull base. For reconstruction of the skull base, 3 types of fascial flaps can be harvested: a laterally based temporoparietal flap, a laterally based temporalis flap with pericranium, and a smaller frontal pericranial flap. Selection of these flaps is tailored to the extent and location of the skull base defect. The pericranial flap can be designed based on an axial blood supply. The anteriorly based flap receives its blood supply primarily from the supraorbital and the supratrochlear arteries. It can be widely based using a bilateral blood supply or it can be designed unilaterally. In addition to axial flaps, the highly vascular nature of this layer allows the design of a multitude of randomly based flaps that can be used for local transfer and repair. However, pericranial flaps of considerable size may be based on either side of the temporoparietal skull. Such flap design may be unilateral or bilateral and may include the temporalis fascia inferiorly. D: Intraoperative planning of a dual flap design of pericranium. In this case, the pericranium is intact entirely and can be used for various flap designs. The cuts are planned to elevate an anteriorly based pericranial flap as well as a temporoparietal flap. E: The dual flap design based anteriorly on the supratrochlear and supraorbital arteries and the laterally based temporalis muscle fascia-pericranial flap based on deep and superficial temporal vessels. The dual flap design enables multilayered closure with various vascularized tissue, which reduces the likelihood of flap failure and CSF leak and brain sagging. F: The temporalis muscle (arrow) itself usually does not need to be used for tissue transfer and can be sutured back to the anterior part of the temporal fossa (asterisk), thereby avoiding postoperative temporal fossa hollowing and poor cosmesis. A notch is drilled laterally into the squamous temporal bone to allow proper rotation into the cranial cavity and avoid vascular compromise of the pedicle. Ant. = anterior; $\mathrm{m}$. = muscle. Figure is available in color online only.

was introduced and used via an endonasal approach..$^{17,24,26}$ This versatile and highly vascularized NSF provides a large surface area with a superior arc of rotation, which can be obtained easily with an endoscopic endonasal approach. These qualities are particularly beneficial for the reconstruction of skull base defects. Therefore, of the local and regional vascularized flaps, the NSF has become the workhorse of endonasal skull base reconstruction, ${ }^{24,26}$ and endoscopic repair with use of the vascularized pedicled $\mathrm{NSF}$ is now considered the gold standard for most CSF leak repairs, because it is safe and effective. ${ }^{19,29}$

\section{"Dual" and "Triple" Combination Flaps}

Persistent CSF leaks after previous attempted repair can be challenging to manage, and the literature that evaluates the use of combination flaps for multilayer closure of 
TABLE 2. Comparison of various pedicled vascularized tissue flaps

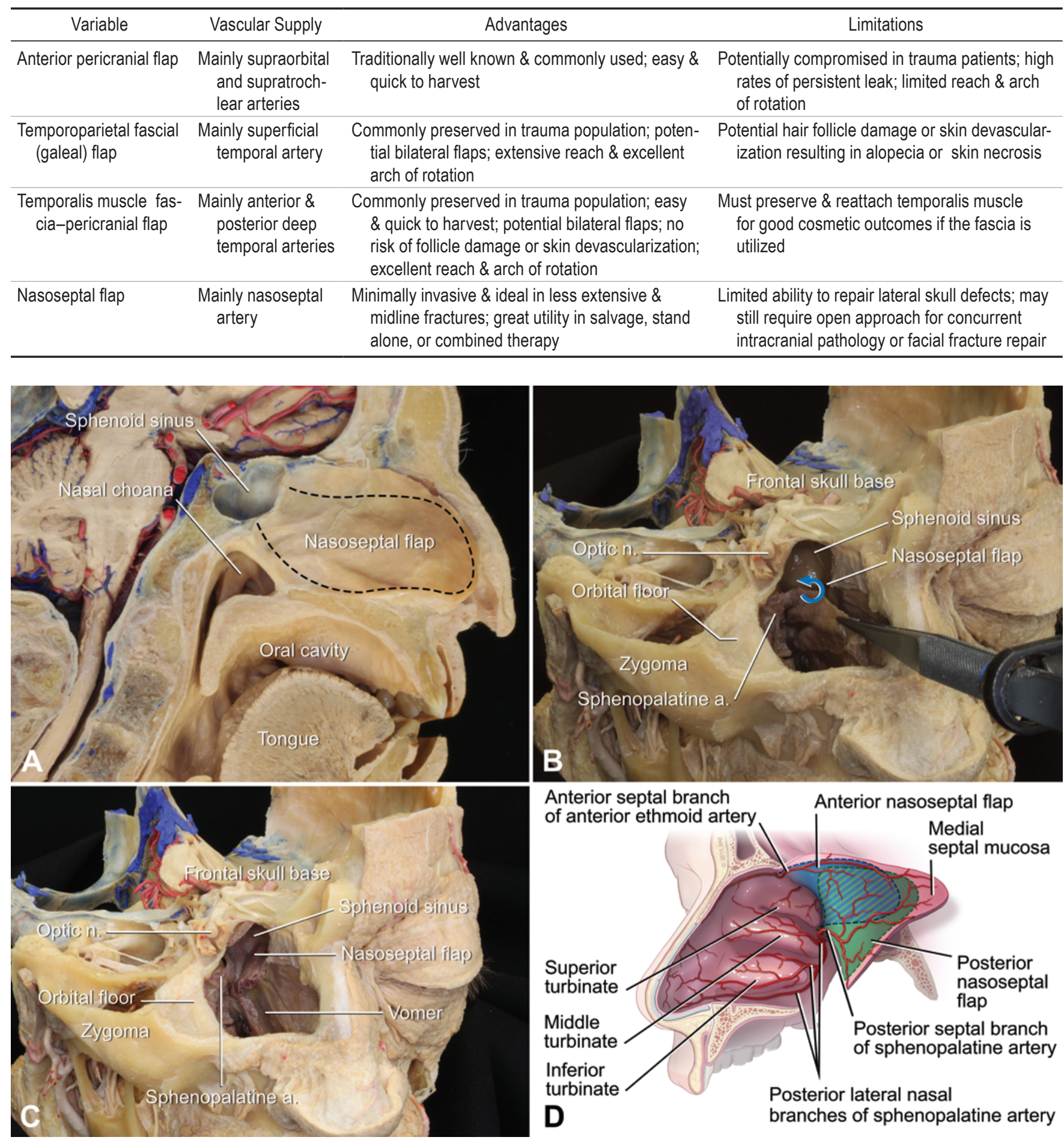

FIG. 7. NSF. A: Medial view of the nasal septum. The dashed line indicates the area of the NSF. The NSF can be harvested from the area just anterior to the middle turbinate at the bone-cartilaginous junction to the sphenoid rostrum. B and C: The relationship between the frontal skull base and NSF. After elevation of the NSF, the flap is rotated into the sphenoid sinus to cover the defect (blue arrow). The posterior vascular pedicle of this flap is formed by the posterior septal arteries. D: Illustration shows the versatility of the NSF schematically. The arterial supply of the nasal septum and variations in the size and location of the highly vascular NSF are shown. Depending on the need, the NSF based on the posterior septal branch of the sphenopalatine artery can be designed to reconstruct defects of the skull base. The anterior NSF may also include the vascular supply of the anterior septal branch of the anterior ethmoid artery (blue area). This vessel is often sacrificed when cuts are made for a more posteriorly designed flap (green area). a. = artery; $\mathrm{n}$. = nerve. Figure 7D copyright of Barrow Neurological Institute from Little AS: Trends and challenges in endoscopic endonasal skull base surgery. Barrow Quarterly 25(1):4-10, 2013. Published with permission from Barrow Neurological Institute, Phoenix, Arizona. 

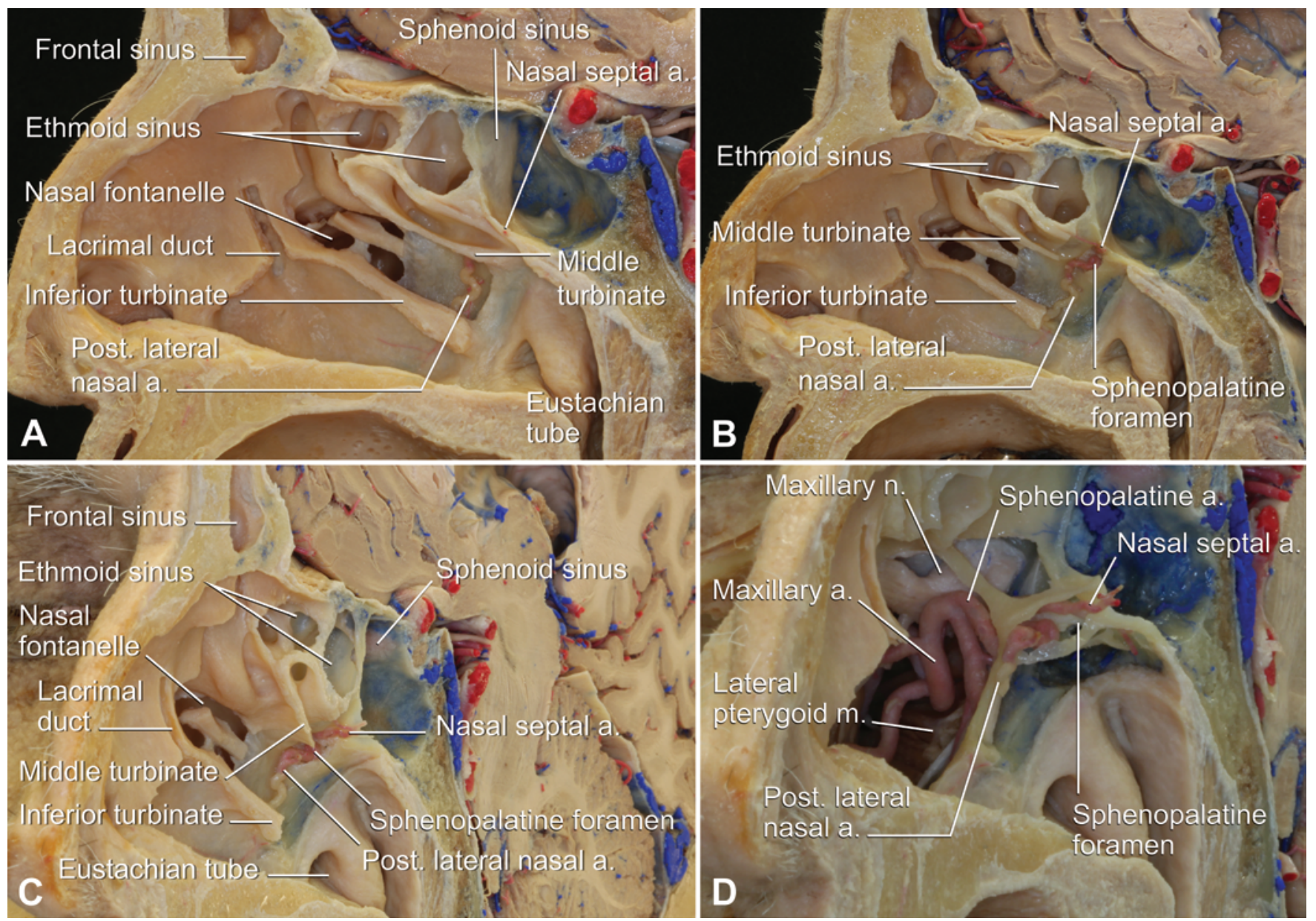

FIG. 8. Step-by-step dissection to show the sphenopalatine artery and its branches. A: Anatomical structures in the nasal cavity. The inferior and middle turbinates have already been removed, and the lacrimal duct and ethmoid sinus have been opened. Removing the mucoperiosteum overlying the medial wall of the maxillary sinus and the palatine bone exposes the posterior lateral nasal artery. The nasal septal artery passes medially toward the nasal septum just anteroinferior to the sphenoid sinus. B: Removing the posterior edge of the middle and inferior turbinates opens the sphenopalatine foramen and exposes the course of the posterior lateral nasal artery. C: Oblique view of the posterior lateral nasal artery after removal of the posterior edge of the middle and inferior turbinates to open the sphenopalatine foramen. D: Removal of the medial and posterior walls of the maxillary sinus and ethmoid sinus exposes the course of the sphenopalatine artery in the pterygopalatine fossa. It is one of the terminal branches of the maxillary artery and passes the sphenopalatine foramen, branching to the nasal septal and posterolateral nasal arteries. $a$. $=$ artery; $\mathrm{m}$. = muscle; $\mathrm{n}$. = nerve; Post. = posterior.

large skull base defects is scant. ${ }^{11,12}$ Multiple flaps for complex skull base defects should be in the armamentarium of comprehensive skull base surgery centers. ${ }^{25,29}$ Multilayer cranial base reconstruction has been reported to lead to satisfactory results in preventing delayed frontal lobe sagging. ${ }^{11,12}$ Eloy et al. ${ }^{11}$ used a triple-layer reconstruction using autologous fascia lata inlay, acellular dermal allograft inlay/overlay, and NSF to reconstruct large cribriform defects in 10 patients. Like these authors, we have abandoned the use of postoperative lumbar drains. None of our patients who underwent a combined endoscopic and microsurgical approach and multilayer closure with 2 or more vascularized flaps required reoperation or had a persistent CSF leak. We have adopted a vascularized pedicled NSF and a fat graft for primary reconstruction as a combination flap and as a salvage method to treat refractory CSF rhinorrhea after previous open repair. In complex fractures and defects, multilayered combination repair with dual or triple flaps can be used effectively, as shown in our patients. This approach obviates the need for vascularized calvarial bone transfer for bone reconstruction of the skull base to prevent flap migration and brain sagging. ${ }^{12,22}$ The dual flap technique uses the anteriorly pedicled pericranium, if available and uncompromised, for frontal sinus repair and laterally based temporalis fascia-pericranial flap for ethmoid and sphenoid fractures. This approach may be augmented further via an endoscopic approach of the exocranial surface and utilization of the triple flap technique, which includes application of an NSF. However, NSF may be reserved for use as salvage therapy if there is a persistent leak after open repair of the endocranial surface, as shown in 3 of our clinical examples. Benefits of this multilayered closure technique using multiple vascularized local flaps are a low likelihood of flap necrosis and 
failure, local harvest of the flap during repair of associated cosmetic defects or tumor resection, and rapid and decisive repair that obviates the need for synthetic material and prevents delayed brain sagging and CSF leak.

\section{Conclusions}

Multilayered closure of cranial base defects with vascularized tissue leads to excellent outcomes. Multiple pedicled flaps are available for reconstitution of the skull base. These vascularized tissue flaps can be used effectively as single flaps or in combination. Dual and triple flap techniques combining the use of various anteriorly and laterally pedicled vascularized flaps and the NSF allow for a comprehensive arsenal in skull base repair and salvage therapy for extensive defects. When patients meet surgical criteria, these repair techniques result in low morbidity and no deaths, with excellent functional and cosmetic outcomes, void of recurrent CSF leaks and meningitis. Knowledge about the surgical anatomy of various flaps for complex skull base defects should be in the armamentarium of skull base surgeons everywhere.

\section{References}

1. Alonso del Hoyo J, Fernandez Sanroman J, Gil-Diez JL, Diaz Gonzalez FJ: The temporalis muscle flap: an evaluation and review of 38 cases. J Oral Maxillofac Surg 52:143-148, 1994

2. Antonyshyn O, Gruss JS, Birt BD: Versatility of temporal muscle and fascial flaps. Br J Plast Surg 41:118-131, 1988

3. Argenta LC, Friedman RJ, Dingman RO, Duus EC: The versatility of pericranial flaps. Plast Reconstr Surg 76:695702, 1985

4. Benzil DL, Robotti E, Dagi TF, Sullivan P, Bevivino JR, Knuckey NW: Early single-stage repair of complex craniofacial trauma. Neurosurgery 30:166-172, 1992

5. Bradley P, Brockbank J: The temporalis muscle flap in oral reconstruction. A cadaveric, animal and clinical study. $\mathbf{J}$ Maxillofac Surg 9:139-145, 1981

6. Brent B, Upton J, Acland RD, Shaw WW, Finseth FJ, Rogers C, et al: Experience with the temporoparietal fascial free flap. Plast Reconstr Surg 76:177-188, 1985

7. Cheney ML, Varvares MA, Nadol JB Jr: The temporoparietal fascial flap in head and neck reconstruction. Arch Otolaryngol Head Neck Surg 119:618-623, 1993

8. Clauser L, Curioni C, Spanio S: The use of the temporalis muscle flap in facial and craniofacial reconstructive surgery. A review of 182 cases. J Craniomaxillofac Surg 23:203214, 1995

9. Collar RM, Zopf D, Brown D, Fung K, Kim J: The versatility of the temporoparietal fascia flap in head and neck reconstruction. J Plast Reconstr Aesthet Surg 65:141-148, 2012

10. Eljamel MS, Foy PM: Post-traumatic CSF fistulae, the case for surgical repair. Br J Neurosurg 4:479-483, 1990

11. Eloy JA, Kuperan AB, Choudhry OJ, Harirchian S, Liu JK: Efficacy of the pedicled nasoseptal flap without cerebrospinal fluid (CSF) diversion for repair of skull base defects: incidence of postoperative CSF leaks. Int Forum Allergy Rhinol 2:397-401, 2012

12. Eloy JA, Shukla PA, Choudhry OJ, Singh R, Liu JK: Assessment of frontal lobe sagging after endoscopic endonasal transcribriform resection of anterior skull base tumors: is rigid structural reconstruction of the cranial base defect necessary? Laryngoscope 122:2652-2657, 2012

13. Friedman JA, Ebersold MJ, Quast LM: Post-traumatic cerebrospinal fluid leakage. World J Surg 25:1062-1066, 2001

14. Gardner PA, Kassam AB, Thomas A, Snyderman CH, Carrau RL, Mintz AH, et al: Endoscopic endonasal resection of anterior cranial base meningiomas. Neurosurgery 63:36-54, 2008

15. Gerbino G, Roccia F, Benech A, Caldarelli C: Analysis of 158 frontal sinus fractures: current surgical management and complications. J Craniomaxillofac Surg 28:133-139, 2000

16. Gossman DG, Archer SM, Arosarena O: Management of frontal sinus fractures: a review of 96 cases. Laryngoscope 116:1357-1362, 2006

17. Hadad G, Bassagasteguy L, Carrau RL, Mataza JC, Kassam A, Snyderman CH, et al: A novel reconstructive technique after endoscopic expanded endonasal approaches: vascular pedicle nasoseptal flap. Laryngoscope 116:1882-1886, 2006

18. Harvey RJ, Nogueira JF, Schlosser RJ, Patel SJ, Vellutini E, Stamm AC: Closure of large skull base defects after endoscopic transnasal craniotomy. Clinical article. J Neurosurg 111:371-379, 2009

19. Harvey RJ, Parmar P, Sacks R, Zanation AM: Endoscopic skull base reconstruction of large dural defects: a systematic review of published evidence. Laryngoscope 122:452-459, 2012

20. Hegazy HM, Carrau RL, Snyderman CH, Kassam A, Zweig $\mathrm{J}$ : Transnasal endoscopic repair of cerebrospinal fluid rhinorrhea: a meta-analysis. Laryngoscope 110:1166-1172, 2000

21. Horowitz JH, Persing JA, Nichter LS, Morgan RF, Edgerton MT: Galeal-pericranial flaps in head and neck reconstruction. Anatomy and application. Am J Surg 148:489-497, 1984

22. Ito E, Watanabe T, Sato T, Ichikawa M, Oda K, Matsumoto Y, et al: Skull base reconstruction using various types of galeal flaps. Acta Neurochir (Wien) 154:179-185, 2012

23. Johns ME, Winn HR, McLean WC, Cantrell RW: Pericranial flap for the closure of defects of craniofacial resection. Laryngoscope 91:952-959, 1981

24. Kassam AB, Thomas A, Carrau RL, Snyderman CH, Vescan A, Prevedello D, et al: Endoscopic reconstruction of the cranial base using a pedicled nasoseptal flap. Neurosurgery 63:ONS44-ONS-53, 2008

25. Kim GG, Hang AX, Mitchell CA, Zanation AM: Pedicled extranasal flaps in skull base reconstruction. Adv Otorhinolaryngol 74:71-80, 2013

26. Liu JK, Schmidt RF, Choudhry OJ, Shukla PA, Eloy JA: Surgical nuances for nasoseptal flap reconstruction of cranial base defects with high-flow cerebrospinal fluid leaks after endoscopic skull base surgery. Neurosurg Focus 32(6):E7, 2012

27. Madhusudan G, Sharma RK, Khandelwal N, Tewari MK: Nomenclature of frontobasal trauma: a new clinicoradiographic classification. Plast Reconstr Surg 117:2382-2388, 2006

28. Mincy JE: Posttraumatic cerebrospinal fluid fistula of the frontal fossa. J Trauma 6:618-622, 1966

29. Patel MR, Taylor RJ, Hackman TG, Germanwala AV, SasakiAdams D, Ewend MG, et al: Beyond the nasoseptal flap: outcomes and pearls with secondary flaps in endoscopic endonasal skull base reconstruction. Laryngoscope 124:846-852, 2014

30. Rhoton AL Jr: The anterior and middle cranial base. Neurosurgery 51 (4 Suppl):S273-S302, 2002

31. Rodriguez ED, Stanwix MG, Nam AJ, St Hilaire H, Simmons OP, Christy MR, et al: Twenty-six-year experience treating frontal sinus fractures: a novel algorithm based on anatomical fracture pattern and failure of conventional techniques. Plast Reconstr Surg 122:1850-1866, 2008

32. Rose EH, Norris MS: The versatile temporoparietal fascial flap: adaptability to a variety of composite defects. Plast Reconstr Surg 85:224-232, 1990 
33. Scher RL, Cantrell RW: Anterior skull base reconstruction with the pericranial flap after craniofacial resection. Ear Nose Throat J 71:210-212, 215-217, 1992

34. Scholsem M, Scholtes F, Collignon F, Robe P, Dubuisson A, Kaschten B, et al: Surgical management of anterior cranial base fractures with cerebrospinal fluid fistulae: a single-institution experience. Neurosurgery 62:463-471, 2008

35. Snyderman CH, Janecka IP, Sekhar LN, Sen CN, Eibling DE: Anterior cranial base reconstruction: role of galeal and pericranial flaps. Laryngoscope 100:607-614, 1990

36. Taha M, Carroll T, McMahon J: Vascularized temporoparietal fascial flap for the treatment of a traumatic cerebrospinal fluid fistula in the middle cranial fossa. Technical note. J Neurosurg 111:393-395, 2009

37. Tellioğlu AT, Tekdemir I, Erdemli EA, Tüccar E, Ulusoy G: Temporoparietal fascia: an anatomic and histologic reinvestigation with new potential clinical applications. Plast Reconstr Surg 105:40-45, 2000

38. Zhang X, Wang EW, Wei H, Shi J, Snyderman CH, Gardner PA, et al: Anatomy of the posterior septal artery with surgical implications on the vascularized pedicled nasoseptal flap. Head Neck [epub ahead of print], 2014

\section{Disclosures}

The authors report no conflict of interest concerning the materials or methods used in this study or the findings specified in this paper. Dr. Sun is supported by the Christopher Getch Fellowship awarded by the Congress of Neurological Surgeons.

\section{Author Contributions}

Conception and design: Safavi-Abbasi. Acquisition of data: Safavi-Abbasi, Komune, Archer. Analysis and interpretation of data: Safavi-Abbasi, Little. Drafting the article: Archer, Sun, James. Critically revising the article: Safavi-Abbasi. Reviewed submitted version of manuscript: Spetzler, Theodore, Rhoton. Administrative/technical/material support: Komune, Little, Sughrue. Study supervision: Spetzler, Safavi-Abbasi, Theodore, Nakaji, Rhoton. Specimen dissection: Komune.

\section{Correspondence}

Robert F. Spetzler, c/o Neuroscience Publications, Barrow Neurological Institute, St. Joseph's Hospital and Medical Center, 350 W. Thomas Rd., Phoenix, AZ 85013. email: neuropub@ dignityhealth.org. 